\title{
Selby diversion of the East Coast Main Line: construction
}

\author{
R. W. Collingwood and T. H. Fenwick
}

\section{Mr Fenwick}

Fig. 21 illustrates one of the defects discovered in some of the large diameter bored piles involved in the bridge construction. Three main lessons may be learned from these defects.

(a) The value of $10 \mathrm{kN} / \mathrm{m}^{2}$ for ground cohesion normally adopted to determine whether permanent liners or only temporary liners are required for casing the pile bore may be too low. It would be more prudent to use a higher value, for example $15 \mathrm{kN} / \mathrm{m}^{2}$.

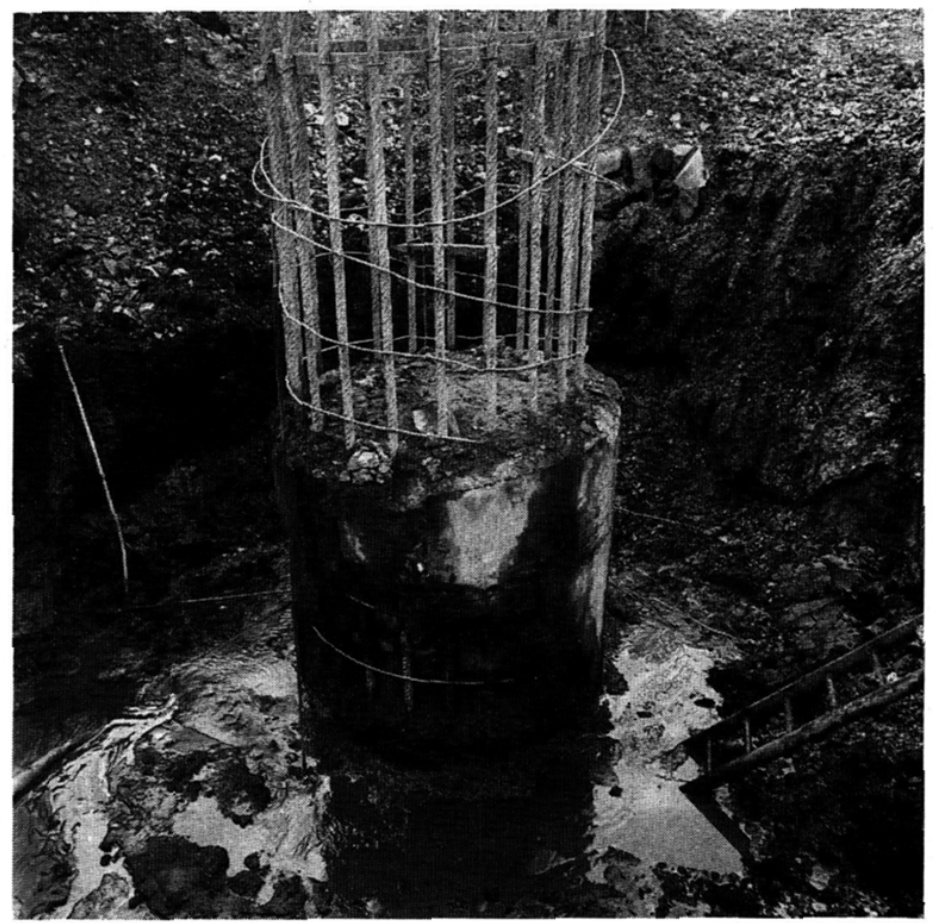

Fig. 21. Defect in pile

Paper published: Proc. Instn Civ. Engrs, Part 1, 1985, 78, Feb., 49-84. 
(b) Great care is needed in the construction of concrete bored piles cast under bentonite, and specialized equipment should be used.

(c) The results of non-destructive testing of piles should be critically inspected. They are not fail-safe.

93. Of the 286 box beams manufactured for the bridge decks, 94 had a bottom flange thickness of $140 \mathrm{~mm}$, compared with the $150 \mathrm{~mm}$ specified. The design was for a conventional precast concrete box section. It would be interesting to know how many similar beams have been manufactured in the past with reduced flange thicknesses, and whether the owners of the beams are aware they have such beams. The main lessons learned from that experience are that

(a) care is required in the manufacture of box beams, particularly with regard to forming the box voids

(b) a positive method of checking the bottom flange thickness of precast box beams should be incorporated in the design.

\section{Mr Collingwood}

Two of the principal aims of the construction were the creation of a railway which opened at high speed and required minimum future maintenance. Careful selection and placing of fill material, monitoring of earthwork performance by geotechnical instrumentation and accurate levelling and compaction of ballast were the means of achieving these aims.

95. Experience so far has shown that these methods have been successful. Riding quality has been good and only minimal maintenance has been necessary.

\section{Mr P. G. Payne, Project Manager for ECML Electrification}

The 'Business Heads of Agreement' between British Railways (BR) and the National Coal Board (NCB) for the Selby diversion included the following provisions: the British Railways Board Regional Chief Civil Engineer was to be the Engineer for the works; the NCB would fund the project; and BR would appoint a Project Manager and the NCB a Liaison Civil Engineer. My involvement in the Selby diversion as Project Manager therefore had some interesting aspects.

97. As $£ 48.4$ million of the $£ 60$ million estimate was civil engineering expenditure, I was appointed with direct responsibility to the Regional Chief Civil Engineer, and not the Regional Planning Manager as would be the normal arrangement. The post was given specific responsibility inter alia for co-ordination of BR staff consultation for the diversion, the NCB terminal at Gascoigne Wood, and associated re-signalling works.

98. The NCB funded the diversion as an element of the Selby Coalfield and this called for appropriate financial reporting to both the BR and NCB managements. The project was authorized by both Boards at an agreed base date value, and the NCB agreed to use BRB's inflation indices.

99. The NCB retained two combined consultant quantity surveying firms - to prepare the $£ 30$ million civil engineering contract and carry out post-contract work in liaison with BR's liaison quantity surveyor. This team also prepared tender reports on all civil and signalling contracts, and these were agreed by the NCB before any contract was let.

100. In liaison with the consultant quantity surveyor, the $23 \frac{1}{2} \mathrm{~km}$ site was split into sections for contract construction of earthworks, drains, fences, bridges and roadworks, each of approximately $£ 2$ million in value. The contract documents 
and all monitoring were then carried out on a 'work section' basis, these sections being recognised by both the British Rail Board and the NCB.

101. At each 4-weekly interval a cost monitoring statement was prepared showing the expenditure in each work section during the previous and current periods, variations incurred in the current period, contractual claims and a calculated anticipated final cost. All costing was done at contract base price and the inflation element up to the date of report stated. Each report also included a project overview, normally made by myself, and the BR quantity survey of the anticipated final cost, which reflected anticipated changes that had not at that stage been subject to a formal variation order or anticipated changes of scope which had a cost effect.

102. Monitoring claims caused problems in accurate costing. Contract claims received by the Engineer were also reported on a 4-weekly basis, together with an Engineer's assessment of the ultimate payments due to the contractor. The difficulties were assuring BR and the NCB management that all claims had been made by the contractor, and in apportioning a notional cost with the great degree of accuracy which the Engineer considered proper under the terms of the contract.

103. A Joint Contract Liaison Group was established including myself, NCB Liaison Civil Engineers, BR engineers involved in superintending contracts, and consultant quantity surveyors, which met to discuss the 4-weekly cost monitoring statement. By this means any variance from contracts was monitored for acceptance, or otherwise, by the NCB. Contract variance was thus recognized at the time, and anticipated final project cost revised to the same time-scale. These arrangements gave close and current cost control throughout the contracts, and similar principles were applied to works carried out by BR staff.

104. The road haulage of the large quantities of material involved (1.75 Mt of rock and $1 \mathrm{Mt}$ of common fill) was a formidable challenge. The NCB had limitations on the use of highways in the area imposed on them, and had to report quarterly tonnage figures to the planning authorities. BR were committed to do the same, but negotiations with the planning authority before tenders were issued enabled tenderers to prepare a tender programme.

105. When the contract was let the contractor was thus involved in discussions with the planning authorities and a firm haulage plan and reporting procedure was arranged which formed the basis of the planning programme. In the event, much of the common fill was acquired from adjacent borrow pits and conveyed along the formation haul road. The Paper has described the initial thrust to establish an all weather haul road by November 1980 which gave rise to the heaviest rate of fill import. Road tonnages were reported to the Selby Coalfield Joint Co-ordination Committee.

106. Paragraphs 60-73 of the Paper describe the problems encountered with bored piling and the difficult and ingenious remedial works carried out on them, and to the problems of precasting large hollow-box concrete beams. Whether a fully reliable method of non-destructive testing for concrete piles and beams can be developed remains to be seen, but significant lessons were learnt on this project.

\section{Mr G. J. C. Jebb, Principal Quantity Surveyor to the British Railways Board}

I was involved at the beginning of this project in some of the pre-contract negotiations, and later at the end of the project in the post-contract negotiations. What is missing from the Paper is something about the finance.

108. The NCB authorized this project for an overall cost of $£ 60$ million, and it 
was finally completed at an actual cost of $£ 63$ million, $£ 6$ million of which was fluctuation. The civil engineering contract was placed at $£ 28.1$ million, and the final cost was $£ 34.5$ million, including inflation of $£ 6$ million. The contract was finished three months ahead of programme to specification, time and cost, and in my opinion no Client can ask more of his designer than that. All in all it was a very creditable performance by the designers, supervisors and contractors.

109. In large measure the success of the project hinged on the good relationship that existed between BR and the contractor's teams, and more especially the team that carried out the project on the site.

110. Part of that team included the quantity surveyor. It is not unusual today to have quantity surveyors involved in major civil engineering projects, but what is significant and unusual in this project is that the NCB decided that they would appoint their own consultant quantity surveyor to work under the direction of the Engineer, yet still reserve some responsibility for itself. The intention of this form of appointment was twofold: it helped to protect the NCB's interests within the project and the contract and, at the same time, it ensured a technical audit of the money being spent in its name.

111. The consultant quantity surveyor was selected under competitive conditions by a panel representing the NCB and BR. I was one of the interviewers, and in the final count, due to a number of circumstances, the consultancy was taken on by a joint venture organization consisting of two London-based professional quantity surveyors. These were two parterships, both of whom have had considerable experience in civil engineering work: Langdon \& Every, who have worked a great deal for British Railways and knew our ways and our work, and Norveil \& Partners, who have considerable experience in NCB work. Each of these firms had their own particular role to play in the overall project, and I would like to acknowledge the professionalism used by these consultants in a situation of this nature.

\section{Mr A. W. Berryman, Langdon and Every/Norveil and Partners}

Good cost control depends on good co-operation between the Client, engineers, quantity surveyors and contractor, and on this project we were especially fortunate, particularly in view of its considerable size and complexity. Our duties were first of all to help with the preparation of the initial budget estimates, to cost-check the evolving design against the budget estimates during the pre-construction stage, and then to prepare approximate bills of quantities. At the construction stage we had then to re-measure the work as executed in conjunction with the contractor, to prepare interim valuations and interim monthly cost control statements (which were extremely complex), and to assist the Engineer in the administration of claims. The idea behind this was to take as much weight as we possibly could off the engineers' shoulders, so that they in turn could concentrate on questions of design, supervision and the solving of everyday construction problems. We had the good fortune of an early appointment, which meant that we could prepare the preliminary estimates and the tender documents in close conjunction with each other. This in turn meant that we could achieve early target dates while keeping off the programme's critical path.

113. For quantity surveying purposes the $23 \frac{1}{2} \mathrm{~km}$ long site was parcelled up first of all into geographical areas, and then into major elements within those areas, such as groups of bridges, and then into still further elements such as individual bridges. This system worked well. It enabled comparison of costs right 
the way through from start to finish, comparing like with like, and the system seemed to benefit site administration generally as much as it benefited the quantity surveying.

114. The financial authority for the civil engineering contract was $£ 28.9$ million, the contract sum was $£ 28.1$ million and the final cost was $£ 28.57$ million. These totals include all extras mentioned in the Paper, and the resolution of all claims. The reasons behind this result were threefold. Firstly, good, keen competitive tenders helped considerably against the original budget. Secondly, the contractor performed extremely well in conjunction with the engineers in finding economic solutions to immediate problems such as temporary works, difficult site conditions, and, particularly, how to import the tremendous quantity of fill needed. They did so well at this that before long there was a potential saving on a number of provisions in the budget and tender documents. Thirdly, the engineers used great skill in balancing extras against omissions.

115. We, too, found the use of computers helpful. They were used particularly in the complicated fill volume calculations. Computers were also used for preparing various parts of the final account, and in turn the contractor used his own computer to prepare his own applications for interim valuations during the running of the job.

\section{Mr M. Couchman, A. Monk \& Co. Ltd}

The building of this contract was enjoyable but not without problems. The thing I particularly liked about it was the way in which the problems were tackled. One of the reasons that the job was in budget was that the problems were tackled properly and responsibly by everybody. That is one of the reasons why the project was finished well, and I would pay tribute to all the people who worked on it.

117. In order to comply with the contract conditions on the use of the roads to the site, the bulk of the rock was imported via the M62 and A19, although it only came along the A19 for about 4 miles. We built a slip road into the site, and used the site as a haul road. This two feet of rock was driven right through the site in the first summer so that we had a haul road to do all the rest of the work. The operation went so smoothly that we had letters from people in the local villages afterwards saying how surprised they were to find that the rock had all been imported, because they were still waiting for the problems to arise. Credit is due to the people on the site for the efforts they made.

\section{Dr W. G. K. Fleming, Cementation Piling \& Foundations Ltd}

The Paper states that two independent non-destructive testing methods were used to look at the defects which occurred in these piles. In addition, we also tested some of these piles using the TNO (Netherlands Technical Organization) sonic method. These were the first big piles we had tested by this method, and it was probably a little premature in relation to our experience of the system. It was not particularly helpful for two reasons.

119. Firstly, these were big piles. Any applied excitation to the head of a pile takes a little time to affect the whole of the pile section-it spreads out as it goes down. Hence it is not easy to distinguish peripheral inclusions in a pile near to the pile head, within the top one or two pile diameters. This is not a problem for small piles.

120. Secondly, an inclusion in a pile has to be of some reasonably significant proportion of the pile area to be seen as a major source of reflection. In other 


\section{DISCUSSION}

words, the sensitivity of the system to a given size of inclusion-and this is true of all integrity testing systems-decreases as the pile diameters increase. However, there has been a marked improvement in the electrical sensitivity of these systems since this work was carried out four years ago. We currently operate an improved system based on analogue signal processing, but the new system which we are about to introduce is fully digitalized, and returns a very high quality pure signal which allows each pile to be analysed by computer simulation when required. Its sensitivity is several times greater than any of the other systems we know of. The system is based on a Motorola 68000 processor. Extensive experience of integrity testing has taught us a great deal, not only about the results of any system but about when to use it and when not to use it, which is perhaps more important.

121. Figures 22 and 23 indicate that there was a high piezometric head at the Selby site. One of the most important things in working with bentonite is to have sufficient backhead against groundwater. If the groundwater level is near to the surface, then the bentonite head must be above the surface, and in this particular case the casings were raised above ground. There is a platform round the top of the casing where men can work. Hanging on the crane in Fig. 22 is the airlift which was used to clean the pile bases at Ryther.

122. Figure 24 shows the bottom end of the airlift. The usual type of airlift

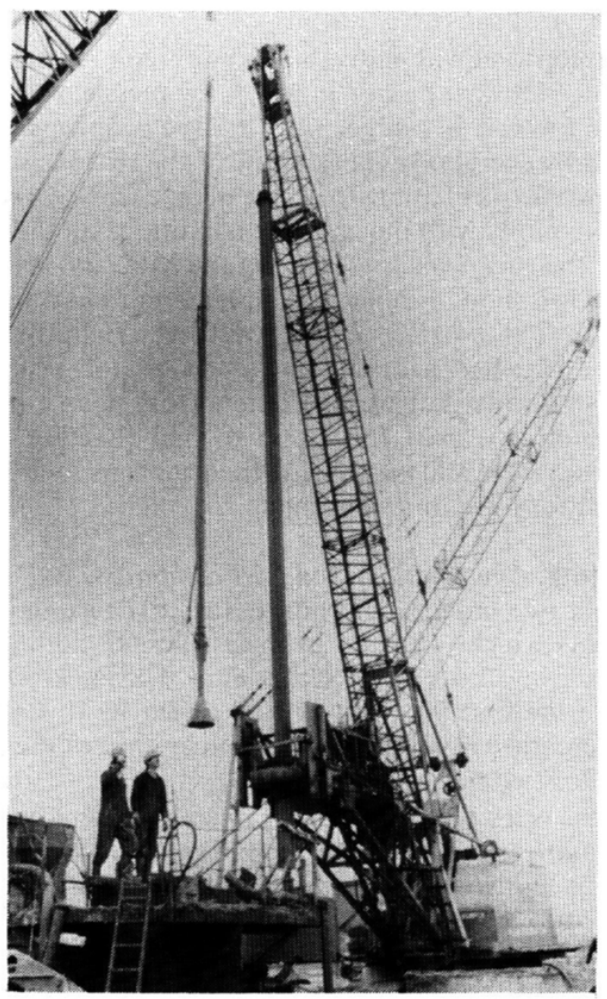

Fig. 22. Airlift hanging on crane 


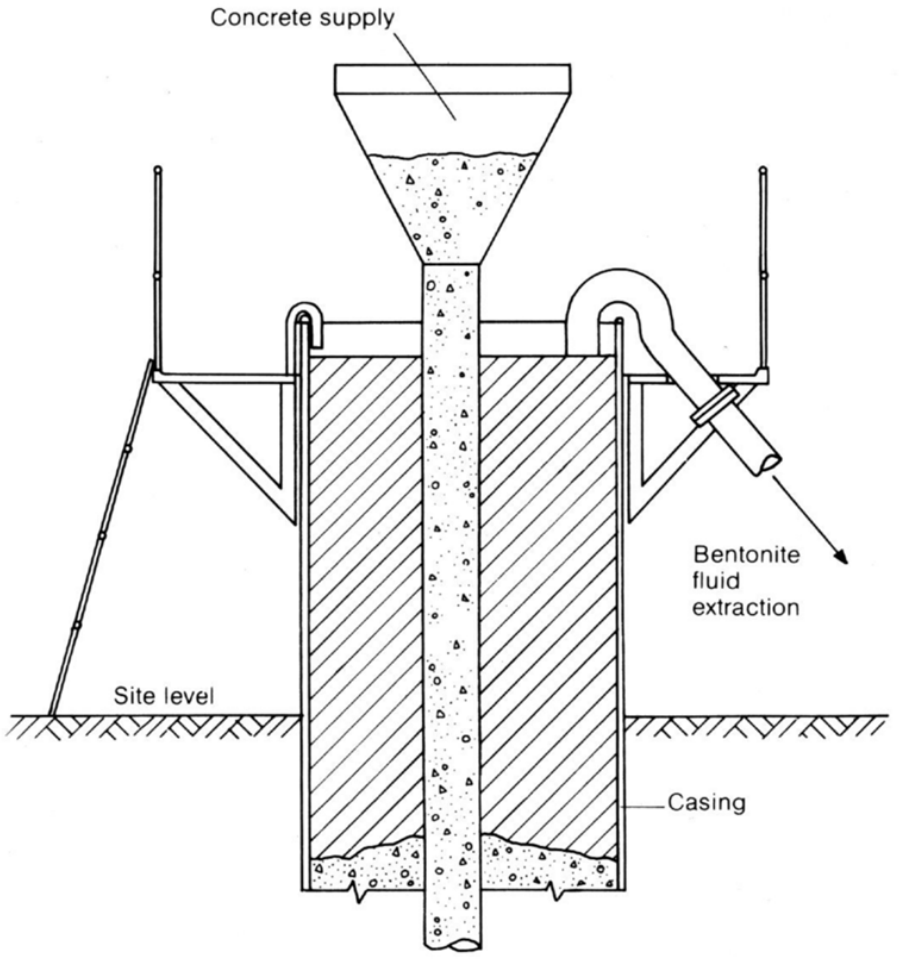

Fig. 23. Elevated working platform and fluid extraction method

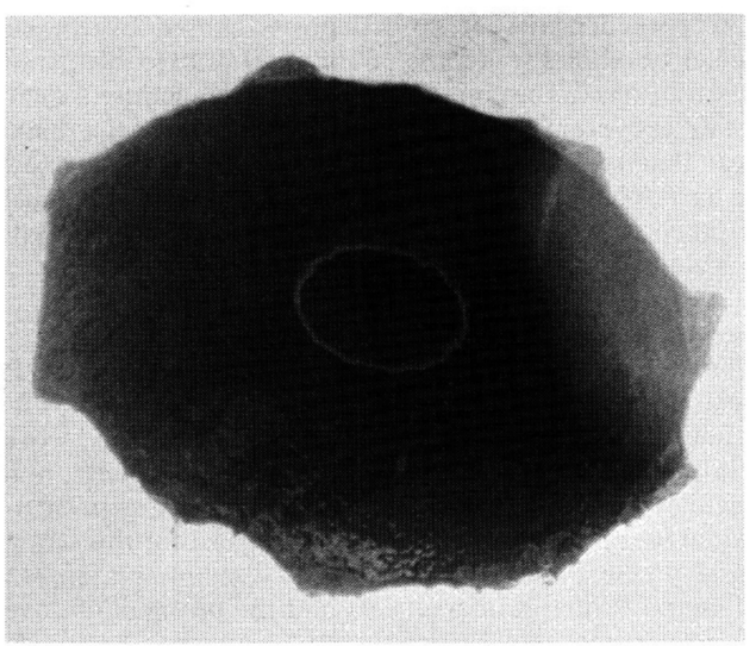

Fig. 24. Bottom end of airlift 


\section{DISCUSSION}

simply has a pipe which comes straight down into the bottom of the hole. If you use a small pipe in a large hole, however, you tend to draw in fine material immediately adjacent to it. This airlift is designed so that when it operates, the fluid is drawn down underneath the edge of the skirt across the bottom of the hole, and then goes up the pipe. In this way a much improved cleaning system is obtained. It is believed by some that one can clean simply by putting an airline into the pile base. This cannot be done; some more advanced type of airlift equipment is needed.

123. Figure 23 shows a simple device which we used to maintain the level of the bentonite constant. It is all too easy, particularly when concrete is rising, to draw off too much bentonite. Spilling of bentonite over the edge of the casing and flooding the site is to be avoided, so a hosepipe is often put in. Bentonite must not be drawn too far, and a simple inverted U-tube over the edge of the casing was used to keep the head of bentonite at a set level.

\section{Mr S. Thorburn, Thorburn Associates}

Figure 25 illustrates the piston effect referred to in $\$ 62(\mathrm{~d})$. If the bucket is withdrawn quickly, not only is an area of low pressure obtained but, if there is only a narrow annulus between the sides of the bucket and the walls of the bore, high scour velocities will result. This could cause instability and erosion of the walls and in a sand material overbreak may occur. This is overcome by introducing relief ducts within the bucket and removing the bucket very slowly, so that the bentonite liquid can pass through smoothly. If care is taken, uniform and stable pile bores can be formed.

125. The next problem is that pile bores must be clean immediately before placing concrete. A long delay may cause sediment to come out of suspension in the bentonite and fall to the base of the pile bore. Despite there being reinforcement in the bore, an airlift can be quickly lowered and the base cleaned once again. This is the advantage of an airlift (Fig. 26).

126. Figure 27 shows the dramatic effect of the removal of excess volumes of sand on the relative densities of sand deposits caused by the sinking of two $150 \mathrm{~mm}$ diameter boreholes to depths of about $20 \mathrm{~m}$ by cable percussion drilling methods. The variations in the cone penetration resistance are a clear indication of the removal of excess volumes of sand, causing loosening of the thick sand layer $C$. It is of interest that loosening of the relatively thin sand layers $A$ and $B$ also occurred. The harmful effect of sinking large diameter bores in an urban situation, if care is not taken to avoid removing excess volumes of material due to overbreak, can be imagined.

\section{Mr F. H. Hughes, Cementation Piling \& Foundations Ltd}

The Temple Hirst embankment drains are described in $\S 23$ of the Paper. On this site deep vertical drainage was used to improve consolidation of soft soils. Cementation Piling and Foundations Ltd had undertaken previous work in soft soils approaching railway over-bridges, but usually for road projects, notably at Sandwich and Queenborough. A trial had been carried out by us prior to the works at Temple Hirst, but we did not get the specialist contract for this work. However, as shown in Fig. 4 of the Paper, the new work commences alongside an existing embankment, so the British Rail engineers had the problem of dovetailing a new embankment into an old one. Inclined drains were thus required. Because our equipment is able to place Mebra drains at an angle to the vertical, we were called 


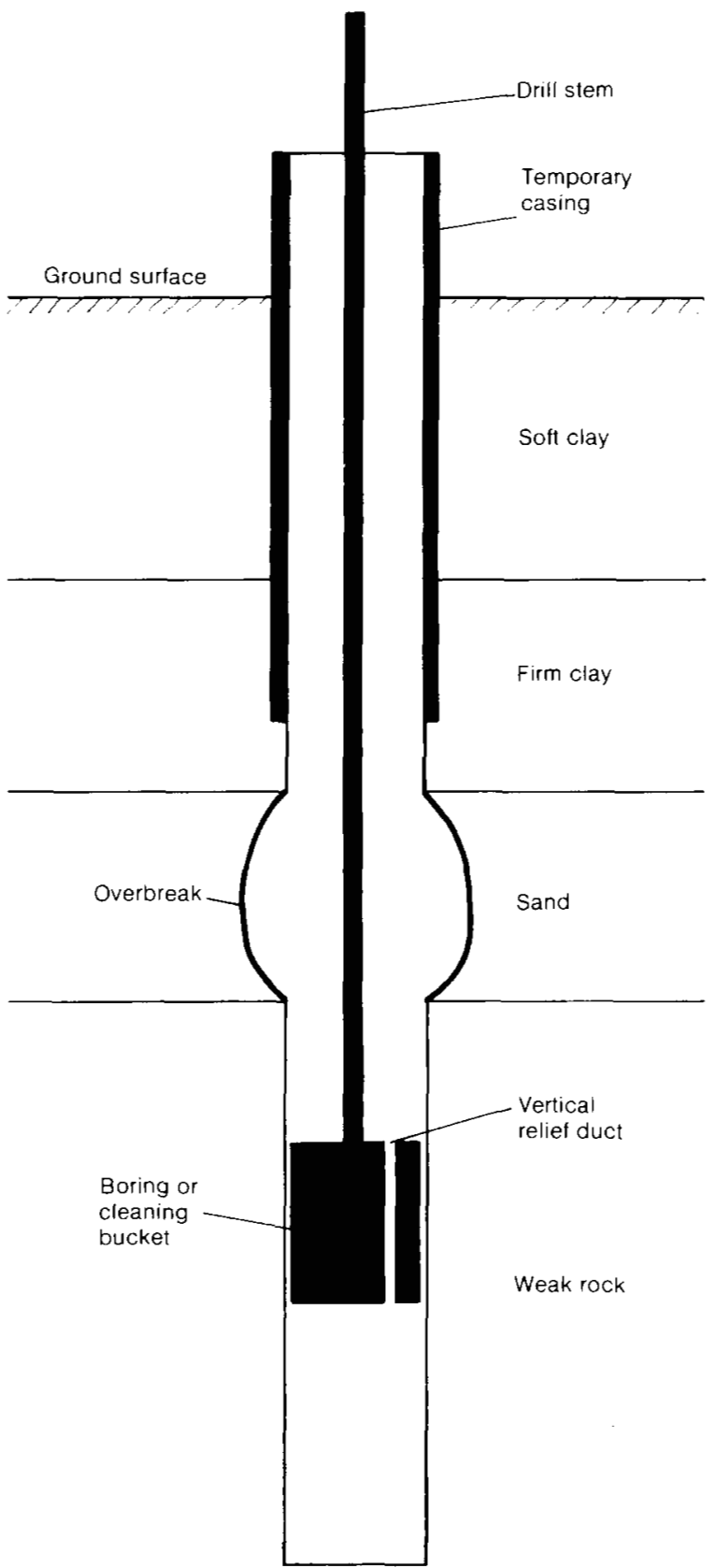

Fig. 25. Piston effect 


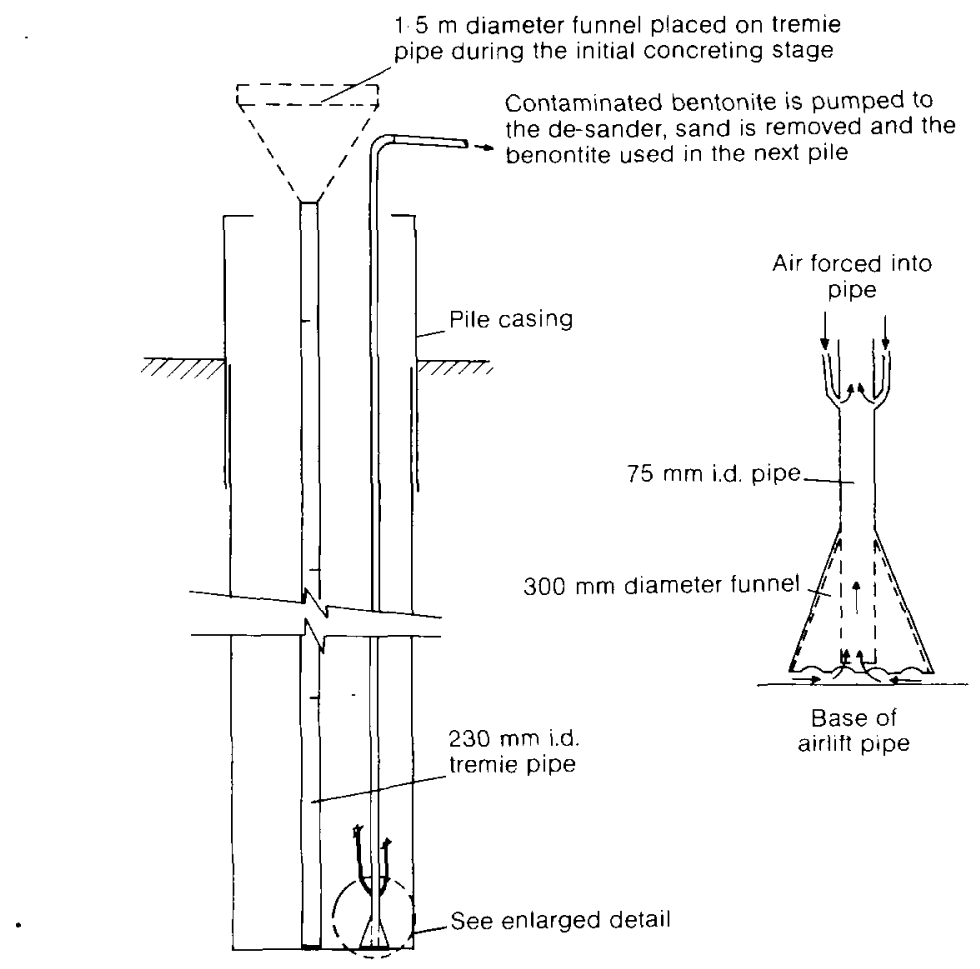

Fig. 26. Cleaning system using airlift

in and placed drains to a maximum gradient of 1 in 28 . We also had to drive through the rock fill on the embankment. This proved difficult, but we were able to penetrate it.

128. A plate anchor was used which was able to survive going through the rock at the surface and become an effective anchor at depth. In all some 1500 drains were put in at 1.5 to $2.5 \mathrm{~m}$ spacings, the maximum depth being $13 \mathrm{~m}$. The main problem encountered during the work was the flooding of the site.

129. Figure 28 shows the type of drain that was used to improve the consolidation characteristics and the load of the soft clays under the embankment. Fig. 29 shows the type of equipment used to push the drains into the ground. The drain comes in a large coil, which is an improvement on the old sand drains which had to be manhandled. By virtue of a 'stitching process', using the mandrel to enter the drain, these can be placed at a rapid rate. Unfortunately at Temple Hirst placement was not so rapid because of the rock obstructions at the surface. When placed the drains are then simply cut off by a pair of garden shears.

130. With regard to site investigation boreholes, it is interesting to hear mention of suction in holes. Disturbance is a continuing problem in cohesionless soils when undertaking investigation boreholes. Standard Penetration Tests made 


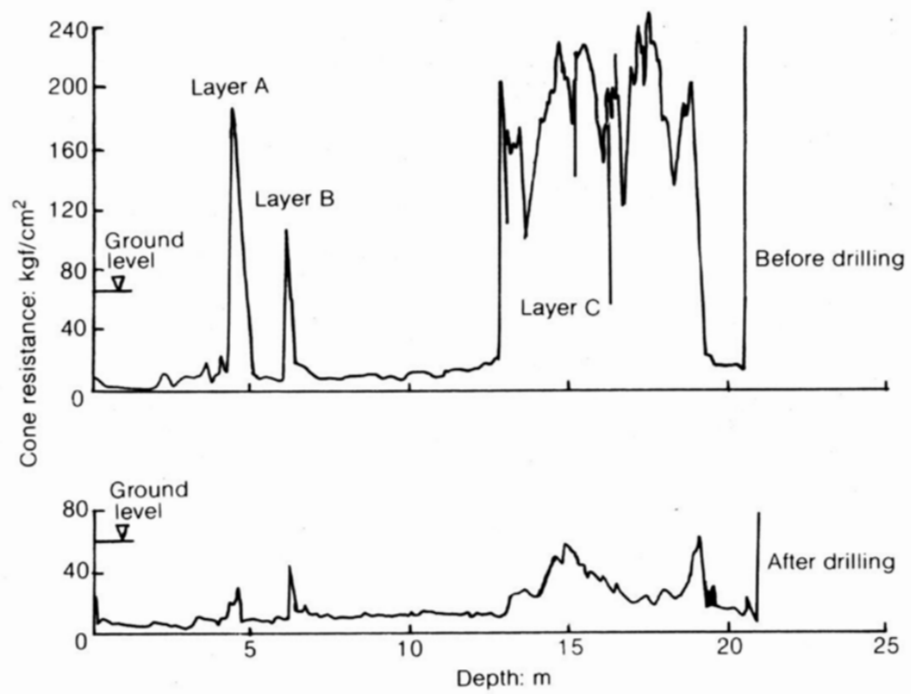

Fig. 27. Effect of removal of excess volumes of sand on relative densities of sand deposits

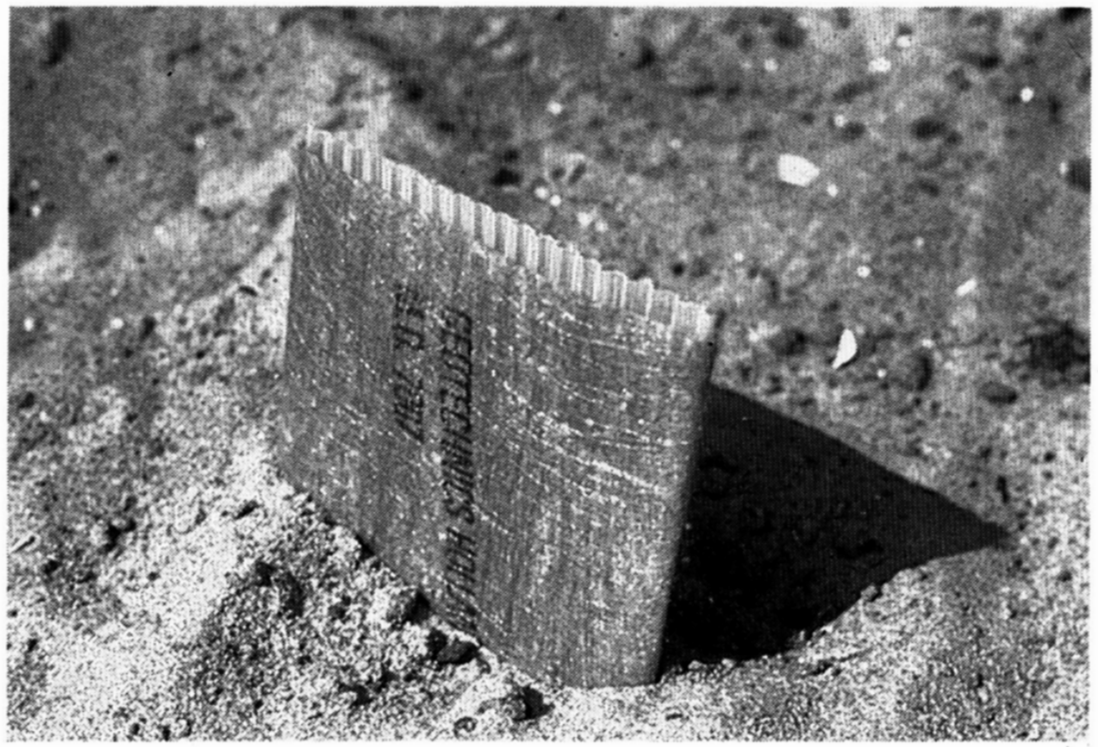

Fig. 28. Drain used to improve clay consolidation 


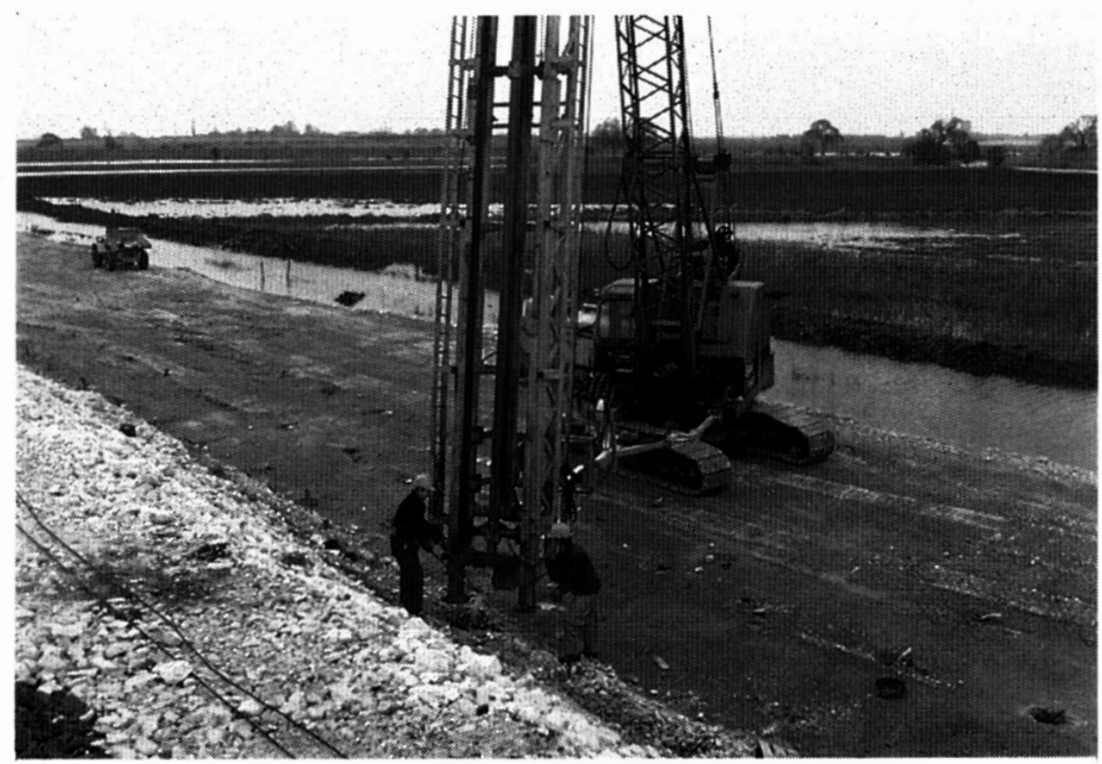

Fig. 29. Pushing drains into the ground

in holes where excessive pumping of the shell has been undertaken are likely to give lower $N$ values than had the crew used perhaps a smaller diameter shell or kept pumping to a minimum.

131. The Authors' useful checklist ( $\S 91$, No. 17) asks if a Standard Penetration Test is required at the base of the pile. If a Standard Penetration Test is carried out at the base of a pile hole dimensions should be given, because normally such tests are carried out in a small diameter bore-hole.

\section{Mr E. F. Humphries, G. Maunsell \& Partners}

Concreting the bottom flange of box beams has always been a problem. Dow-mac use wire ropes wrapped round with polythene sheeting to form the inner core formwork, so that it is possible to see how the concrete travels underneath to obtain the required thickness. Nevertheless, my firm experienced difficulties with such beams and this was one of the reasons that the U-beam was developed. Most bridges these days employ U-beams, for which the thickness at the bottom can be seen at time of manufacture and controlled properly. Shear between beams under a railway bridge deck is not the same as that for a highway bridge, but the top slab connecting U-beams can be made sufficiently stiff to ensure that there is no relative movement between them. Was the use of $\mathrm{U}$-beams considered?

133. The cost of setting up and operation of bentonite plant is usually fairly expensive. Was the use of other methods of piling considered in order to obviate that? The cost of provision of temporary liners going down the considerable depths shown in the Paper would perhaps have been prohibitive. This may be the reason why liners were not used low down - could the Authors confirm that? The 
chance of getting a sounder pile is in fact much better if a permanent liner can be installed a considerable way down.

134. Piling is always a chancy business, as illustrated by a case of bored piling in Stoke-on-Trent. Certain piles were selected and load-tested, and found to be acceptable. Later on the pile cap was excavated, and it so happened that the pile cap had to be taken down considerably below the level of the ground on which the proof load testing had taken place. It was found that over a length about 300 to $350 \mathrm{~mm}$ in several piles there was no concrete whatever. The proof loads had been carried perfectly well by the reinforcement standing in free air or mud. So care has to be taken!

\section{Mr W. M. Lewis, British Rail.}

As stated in the Paper $(\$ 13)$ the contractor established a haul road along the route by laying the bottom $600 \mathrm{~mm}$ of embankment. It was essential to ensure that the vehicles using the haul road did not cause ruts to form in the ground supporting the embankments. The limitation that was placed on the contractor to achieve this is stated in the Paper $(\S 20)$.

136. The haul road had to be shaped continuously by a grader to encourage vehicles to use the whole width of the embankment, and at the same time to clear material falling from the dumper trucks.

137. Before the embankment could be built up to height as withdrawal took place the haul road had to be scarified, and in some places where the fill material had been contaminated it had to be removed and screened before being returned to form the embankment.

138. Travelling over the rail track today it is not possible to distinguish between those places where the haul road ran on the embankment and the bypasses around the cuttings, where no road vehicles ran on the formation.

139. As stated in the Paper ( $\$ 18)$, site investigations were carried out continuously to investigate whether it was necessary to blanket, excavate peat, cut crops or simply to roll the top soil, followed by placing a single layer of Terram 1500 and two $300 \mathrm{~mm}$ layers of rock fill.

140. Investigation had shown that if the upper formation was excavated the result would be to go through into soil that was weaker than the topsoil that was removed. Nevertheless, it was so traditional to specify the total removal of the top $300 \mathrm{~mm}$, and to replace it with rock fill, that it required courage to take the decision not to do so. This made a substantial difference to the costing, and the decision ultimately turned out to be the right one.

\section{Mr G. H. Cope, Fellow}

At the time of the construction I was the Permanent Way Engineer in the office of the Director of Civil Engineering.

142. In my contacts with European railway representatives over the years, I have gained the impression that British Railway permanent way is regarded with mild amusement as being extremely cost effective, which is another way of saying extremely cheap, or perhaps even cheap and nasty. By way of illustration, one can compare the vital statistics of the track on British Railways, of which the Selby diversion is an example, with that which was put down with a great flourish and trumpets by the French Railways (SNCF) on their recently constructed railway from Paris to Lyons (the TGV line).

143. The ballast is about the same thickness as was put down at Selby, but I 
believe that on the French railways ballast of considerably higher wet abrasion resistance is used than is available in this country. The French use twin block sleepers to our mono-block sleepers; there is a continuing argument between British Railways and the European railways, and the SNCF in particular, about the wisdom of twin block sleepers. The important point regarding the sleepers, however, is that whereas the TGV use sleepers at $600 \mathrm{~mm}$ spacing, the sleepers on the Selby diversion have $650 \mathrm{~mm}$ spacing, so we have $10 \%$ fewer of them.

144. The Selby diversion was constructed with $54 \mathrm{~kg} / \mathrm{m}$ rail, and the SNCF and the TGV use $60 \mathrm{~kg} / \mathrm{m}$ rail. It has been reported that maintenance on the TGV now is so minimal that they are able to redeploy half their tamper fleet. For our part, over quite a high proportion of the Selby diversion it has not been necessary to tamp at all in the two years or so since it went into service. So our 'cheap and nasty' railway, at least when laid properly in a green field situation, stands the critical tests of loading just as well as the SNCF railway, even under the heavy axle loads that we use (the Selby diversion carries a 25 -ton axle load, with freight traffic as well as passenger traffic, whereas the TGV carries exclusively passenger trains).

145. Another interesting feature about the railway is that it is laid with the same track spacing $(3.4 \mathrm{~m})$ as the rest of British Railways. The TGV has a track spacing of $4.2 \mathrm{~m}$, and our European colleagues have found it a bit difficult to understand why, in building $23 \mathrm{~km}$ of new railway, we did not provide the sort of track spacing that is common on the continent, which would have enabled us to use track relaying machines and ballast cleaners without having speed restrictions on the opposite line. There are two reasons: the diversion was being paid for by another organization; and there would be no point in being able to use continental machinery on only $23 \mathrm{~km}$ out of about $600 \mathrm{~km}$ main line.

146. With regard to Colton Junction, comparisons could again be made with the TGV. On the TGV line SNCF use turnouts whose crossing angles are much smaller than those used by BR at Colton Junction. The crossing angle on the BR turnout is $1^{\circ} 46^{\prime} 11^{\prime \prime}$ ( 1 in 32.365), compared with $0^{\circ} 52^{\prime} 56^{\prime \prime}$ (approximately 1 in 65) used on the TGV line. The Colton Junction turnouts are $89 \mathrm{~m}$ long; the longest turnouts on TGV are well over $200 \mathrm{~m}$ long. The crossings at Colton are fixed, whereas almost all the crossings on the TGV are swing nose crossings. The main reason for this is that there are only two of these crossings on the whole of the Selby diversion, whereas the number of turnouts on the TGV route runs into scores. Large sums of money can only be spent on the development of exceptional pieces of equipment such as this when there is a large market for them. The market for switches such as those at Colton Junction is such that there are at present only three places on the railway where they exist: two at Colton Junction, and one that was put in as a trial at Soham, near Ely in Cambridgeshire. The $\mathrm{H}$ switch is regarded as the limit of the development of flexible switches using British Rail plain $113 \mathrm{lb}$ rail, and the 1 in 32 fixed crossing represents the ultimate level of development of fixed common crossing. To go faster than that it will be necessary to use the French system of switches made of a special thick webbed tongue rail, and to use swing nose crossings.

147. During the trial work at Soham, it was noted that when the switch was pulled using the mechanical equipment that was available there it would take about two seconds between starting the switch moving at one end and the movement reaching the far end. It was possible to get a situation where an obstruction could be put between the switch rail and the stock rail towards the heel end of the switch; detection would be achieved at the leading end although the back end had 
failed to move. This was because there was so much slack in the mechanisms. In the installation which has gone in at Colton there has had to be a great deal of development by the signal engineer in the hydraulic driving switches, to ensure that the switch drives evenly and detects accurately. The use of a stiffer switch with a thicker web would avoid this problem.

\section{Mr J. E. Spindel, British Railways Board}

Dr Fleming points out that it is not enough to say that various non-destructive testing methods failed to give the required result but that it is also necessary to know why. The same view was taken when these events occurred, and investigations were undertaken to establish the reasons.

149. The non-destructive testing methods used relied variously on

(a) a measurement of the natural frequency of the structure, at very high modes of vibration for the piles (both lateral and longitudinal)

(b) measurement of the velocity of sound in concrete

(c) the reflection of sound waves in concrete.

Calculations with very simple mathematical models showed that neither the frequencies of vibration nor the velocity of sound were sensitive to the local loss of section which had led to exposure of reinforcement. The effects of the local changes in section were completely masked by random variations in the modulus of elasticity of concrete.

150. With hindsight this is not a surprising result, since the velocity of sound depends only on the square root of the ratio of the density of the material to its modulus of elasticity, and the natural frequency of vibration depends on the same parameter and the radius of gyration.

151. This experience suggests that it is essential, before accepting any nondestructive testing method, to establish first of all what kind and size of defect is to be found and then to check whether the test proposed can detect the least of these defects and distinguish it from random variations in the properties measured. This is less a matter of the accuracy and sensitivity of instruments as of the inherent physical properties of the material on which measurements are to be made.

152. The second of these questions should be settled by parametric studies on mathematical models, and only then by physical tests, since the latter are necessarily limited by their cost. It must be recognized that the results of tests, however many, on specimens of largely unknown quality cannot be regarded as a substitute for such an investigation, particularly as the interpretation of many of these is based on undefined criteria described as 'experience'.

153. The other lesson to be learnt is that there is no substitute for a full and proper control of workmanship. The standards required are known: it is merely a matter of ensuring that the contractor exercises sufficient supervision over the work to ensure that they are met. If this requires piling contractors to remember the fluid mechanics they were taught and producers of pre-cast concrete articles to remember that all water has to be kept out of moulds, and that in the concrete severely limited, then so be it.

\section{Mr Collingwood}

The contributions to the discussion by Messrs Payne, Jebb and Berriman concerning cost control and quantity surveying matters fill a gap in the Paper and I thank them for their comments. 
155. Mr Couchman reminds us that the way in which site problems were jointly tackled by Engineers and Contractors alike contributed significantly to the success of the project.

\section{Mr Fenwick}

Mr Hughes commented on the use of Standard Penetration Tests at the base of a pile hole. On the Selby diversion there was a transition from compact sand to cemented sandstone. The pile design needed a 'rock socket'. The SPTs were used to define roughly where the sandstone started and thus the start of the rock socket. It is acknowledged that SPTs are normally carried out in small diameter bores. The Standard Penetration Test is, however, a relatively coarse method of assessing bearing strengths. Also, tests carried out in larger diameter bores will give conservative results compared with those done in the same material in a smaller diameter bore. These factors were taken into account when the piling specification was being established and for this project a minimum ' $N$ '-value of 400 was considered appropriate to 'prove' the adequacy of the sandstone. In practice it was consistently found that the ' $N$ '-values in the sandstone were greatly in excess of this value.

157. In reply to $M r$ Humphries' questions; yes, the use of U-beams among other deck configurations was considered for the viaduct decks. The precast boxbeams were used since it was known the project timescale was tight and it was decided this arrangement using the minimum of site concrete and formwork would provide the most speedy and economical superstructure. In the event this proved very much to be the case. Despite delays due to the piling problems and the need to produce additional beams to replace those with reduced flange thickness, the main viaduct was finished within a few days of the original programmed completion date which was on the contract critical path. The box-beams also facilitated transverse post-tensioning which provided a structurally efficient deck for supporting railway loadings.

158. The use of piling systems other than large diameter bored piling under bentonite was considered. Comparative costs were estimated for driven pile and smaller diameter bored pile methods. Although driven piles were found to be the most suitable method for the overbridges they could not compete on the basis of cost with the large diameter bored piles at the viaduct sites.

159. Mr Humphries is quite correct about the cost of permanent liners. They are very expensive. The piles were cast under bentonite specifically to reduce as far as possible the lengths of such casings and consequently the pile costs. The liner lengths, however, must be determined only after careful consideration of the soil and ground water conditions to ensure the production of sound piles.

160. Sub-structures using driven piles or smaller diameter piles would have required either heavy pile caps or solid piers. Both of these arrangements would have been more costly and time consuming than the simple circular column and cross-head structure adopted. They would also have needed more time to install. 